\title{
Restricted gene flow and subpopulation differentiation in Silene dioica
}

\author{
BARBARA E. GILES*†, ELISABETH LUNDQVIST† \& J ÉRÔME GOUDET‡: \\ †Department of Genetics, Umeå University, S-901 87 Umeå, Sweden and łInstitut de Zoologie et d'Écologie \\ Animale, Université de Lausanne, CH-1015 Lausanne, Switzerland
}

\begin{abstract}
The size of breeding units and the hierarchical population structure of the dioecious perennial herb Silene dioica were investigated on four closely situated island populations in the Skeppsvik Archipelago in northern Sweden. $F$-statistics analyses of nine polymorphic allozyme loci revealed that plants on single islands are divided into many small breeding units, between $0.2 \mathrm{~m}^{2}$ and $6 \mathrm{~m}^{2}$. Hierarchical analyses showed that levels of differentiation among subpopulations within islands $\left(F_{\mathrm{PL}}=0.080\right)$ were about twice as high as among islands $\left(F_{\mathrm{LT}}=0.048\right)$. These results are discussed in the light of what is known about pollen and seed movement in the archipelago.
\end{abstract}

Keywords: gene flow, genetic differentiation, population subdivision, Silene dioica.

\section{Introduction}

The habitats of most species of plants and animals exist as discrete patches on some geographical scale. This patchiness forces individuals into arrays of local populations where mating is more likely to occur among individuals living in the same local population (McCauley, 1995). If these local populations are small and isolated, they may diverge genetically as a consequence of random drift. Moreover, if gene flow is sufficiently restricted, even large continuously distributed assemblages of conspecifics may come to consist of many small breeding units, where deviations from random mating among the units will favour their genetic divergence (e.g. Wright, 1951; Rohlf \& Schnell, 1971; Turner et al., 1982). Significant levels of genetic differentiation among arbitrarily designated local populations have been observed where nearest-neighbour pollination and limited seed dispersal, two forms of restriction of gene flow in plants, have been shown to occur (e.g. Handel, 1983; Williams \& Guries, 1994). Differential selection operating over small spatial scales can also lead to differentiation within populations (see Linhart \& Grant, 1996). The effectiveness of selection, however, is influenced by the degree of subdivision resulting from specific rates and patterns of gene flow (Barton \& Whitlock, 1997). Thus, knowledge about the existence of subdivision, the relative scale on which it occurs and the sizes of breeding units is

\footnotetext{
*Correspondence. E-mail: barbara.giles@genetik.umu.se
}

required for untangling the evolutionary dynamics of a species.

Giles \& Goudet (1997a) studied the distribution of allozyme variation in the dioecious perennial herb Silene dioica among 52 of the naturally founded island populations composing an age-structured metapopulation in an archipelago in the northern Baltic. These islands were differentiated, largely because of genetic differences among the founding propagules, and these differences were not eradicated by continued gene flow. The plants in that study were, however, collected as random samples from each island which means that each island was treated as if it were a single breeding unit. Both global and within-island $F_{\text {IS }}$ values were significantly greater than zero, indicating strong heterozygote deficits within islands (Giles \& Goudet, 1997a). Although two factors, inbreeding and structuring, could account for such deficits, the obligately outbreeding nature of $S$. dioica and the heterogeneity of within-island $F_{\text {IS }}$ (range -0.18 to 0.38 ) values (Robertson \& Hill, 1984) suggested that islands were probably structured into small breeding units. Nearest-neighbour pollination and restricted seed dispersal have been observed on these islands (P. K. Ingvarsson and B. E. Giles, unpub. obs.) thus providing mechanisms by which subdivision could occur. The existence of potential structuring within and among islands also suggests that $S$. dioica populations in this archipelago are subdivided at several hierarchical levels. Because actual rates of gene flow 
among breeding units play a critical role in determining the scale over which breeding units may assume independent evolutionary trajectories (Slatkin, 1985), we felt it essential to investigate the degree of structuring within islands.

We sampled plants from 100 patches distributed over four different islands situated near to each other in the archipelago and asked the following questions. (i) Do the $S$. dioica populations growing on each island consist of several breeding units? (ii) How large are these breeding units? (iii) What are the levels of differentiation within islands relative to the levels among islands? The plants were assayed for nine enzyme loci and analysed with $F$-statistics. Island populations of $S$. dioica are strongly differentiated over a scale of a few metres and the degree of differentiation among these local populations is about twice that among islands. The results are discussed in the context of gene flow.

\section{Materials and methods}

The study system

Silene dioica (L.) Clair. (Caryophyllaceae) is a perennial herb found throughout much of northern Europe including Iceland, the Færöes and northernmost Fennoscandia. This species requires moist, fertile and disturbed habitats and is a member of the earlier stages of primary and secondary successional communities (Baker, 1947; Grime, 1979). Population growth in this diploid dioecious species depends on sexual reproduction. Plants begin reproduction at 2-3 years of age and may live for 5-10 years. Flowering occurs in June and July and bumblebees (Bombus spp.) are thought to be the main pollinators (Kay et al., 1984). In August, mature capsules open at the apex and the seeds, which are then lying free in the bottom, are dispersed by gravity as stems are shaken or broken. Although seeds can germinate in the autumn, most do not until June the following year. At this time, $90 \%$ of the seeds germinate, and after two years, fewer than $1 \%$ of seeds remain ungerminated (Elmqvist \& Gardfjell, 1988) suggesting that seed bank dynamics may not be important for this species.

The study was carried out on islands in the Skeppsvik Archipelago (Fig. 1), located in the Gulf of Bothnia at the mouth of the Sävar River, Västerbotten, Sweden $\left(63^{\circ} 44-48^{\prime} \mathrm{N}, 20^{\circ} 31-33^{\prime} \mathrm{E}\right)$. This archipelago is subject to land uplift $(\approx 0.9 \mathrm{~cm}$ per year) so that new islands are continuously being formed (Ericson \& Wallentinus, 1979). As a result, islands differ in age and stage of primary succession. Silene dioica populations do not establish on islands less than $70-150$ years old and go extinct on islands older than $\approx 350$ years old when coniferous forests have expanded to occupy most of each island. Large continuously distributed populations of $S$. dioica are found in the interim (details in Giles \& Goudet, 1997b).

\section{Choice of islands}

The study islands were chosen to fulfil the following criteria: (i) islands should have similar successional stages to reduce the contribution of variance arising from age/stage differences among islands (Giles \& Goudet, 1997a); (ii) islands should support continuously distributed $S$. dioica populations, because we are interested in seeing whether differentiation occurs where locally restricted gene flow could be the cause; and (iii) islands should be situated in the same area of the archipelago so that some seed and pollen flow is possible among them. Islands 39, 35, 23 and 17 (17 now fused to 23) fulfil these criteria (Table 1, Fig. 1). Although Table 1 indicates that the ages of the populations differ on these islands, they have similar successional stages (Giles \& Goudet, 1997b).

\section{Within-island sampling}

To infer that island populations are subdivided into many randomly mating units, we must show that heterozygote deficits for groups of individuals within spatially restricted areas (patches) within islands are not significantly greater than zero, and that heterozygote deficits among patches are significantly greater than zero (Wright, 1951). Note that as the study organism is dioecious, the expected value of the within-patch heterozygote deficit should be slightly negative and equal to $-1 /(2 n-1)$, where $n$ is the number in a patch (e.g. Cockerham, 1973).

Individuals were collected in the summer of 1994 from 100 patches distributed over the four islands (Table 1). The patches, which were circles $0.5 \mathrm{~m}$ in diameter $\left(0.2 \mathrm{~m}^{2}\right)$, were distributed over as much of an island as possible. Patch size and shape were chosen to imitate the area within which clusters of seedlings are found growing under isolated females (Giles \& Goudet, 1997a). A preliminary survey was carried out to confirm that individuals sampled within patches of this size belonged to the same random mating unit. In the summer of 1993, all individuals were collected from each of six $0.2 \mathrm{~m}^{2}$ patches on island 23. The distances between the centres of these patches varied from 2.8 to $35 \mathrm{~m}$. Levels of differentiation (estimated as $F_{\mathrm{ST}}$ ) among all six patches and between the two patches sepa- 
rated by $2.8 \mathrm{~m}$ were significantly greater than zero and no evidence of within-patch heterozygote deficit $\left(F_{\text {IS }}\right)$ was obtained (data not shown). We thus continued to use $0.2 \mathrm{~m}^{2}$ patches in the 1994 survey but the number of individuals collected from each patch was reduced to 10 so that we could increase the numbers of patches and islands studied. Sampling details and the locations of the patches on each island are given in Table 1 and Fig. 2(a-c), respectively.

\section{Numerical estimates of patch size}

The numbers of adults, juveniles and seedlings were all recorded in 14, 17, and 18 of the patches sampled for electrophoresis from islands 23, 35 and 39, respectively. These developmental stages can be recognized by the size and number of the leaves composing the rosette. Seedlings are plants germinating in the census year; juveniles are prereproductive individuals which have survived at least one winter and have small rosettes. Adults have welldeveloped rosettes with many leaves and have reached reproductive age. These data were collected to provide estimates of: (i) mean numbers of all individuals and (ii) the mean numbers of reproductive individuals, in $0.2 \mathrm{~m}^{2}$ patches. To be as conservative as possible, we used the sum of flowering and nonflowering adults to estimate the numbers of reproductive individuals. Because the accumulated effect of genetic drift depends on the reciprocal of the size of the reproducing population (Falconer, 1989), we use harmonic means to estimate the 'effective' mean numbers of reproductive individuals

Fig. 1 Skeppsvik Archipelago. The study islands are marked in black and identified by number.

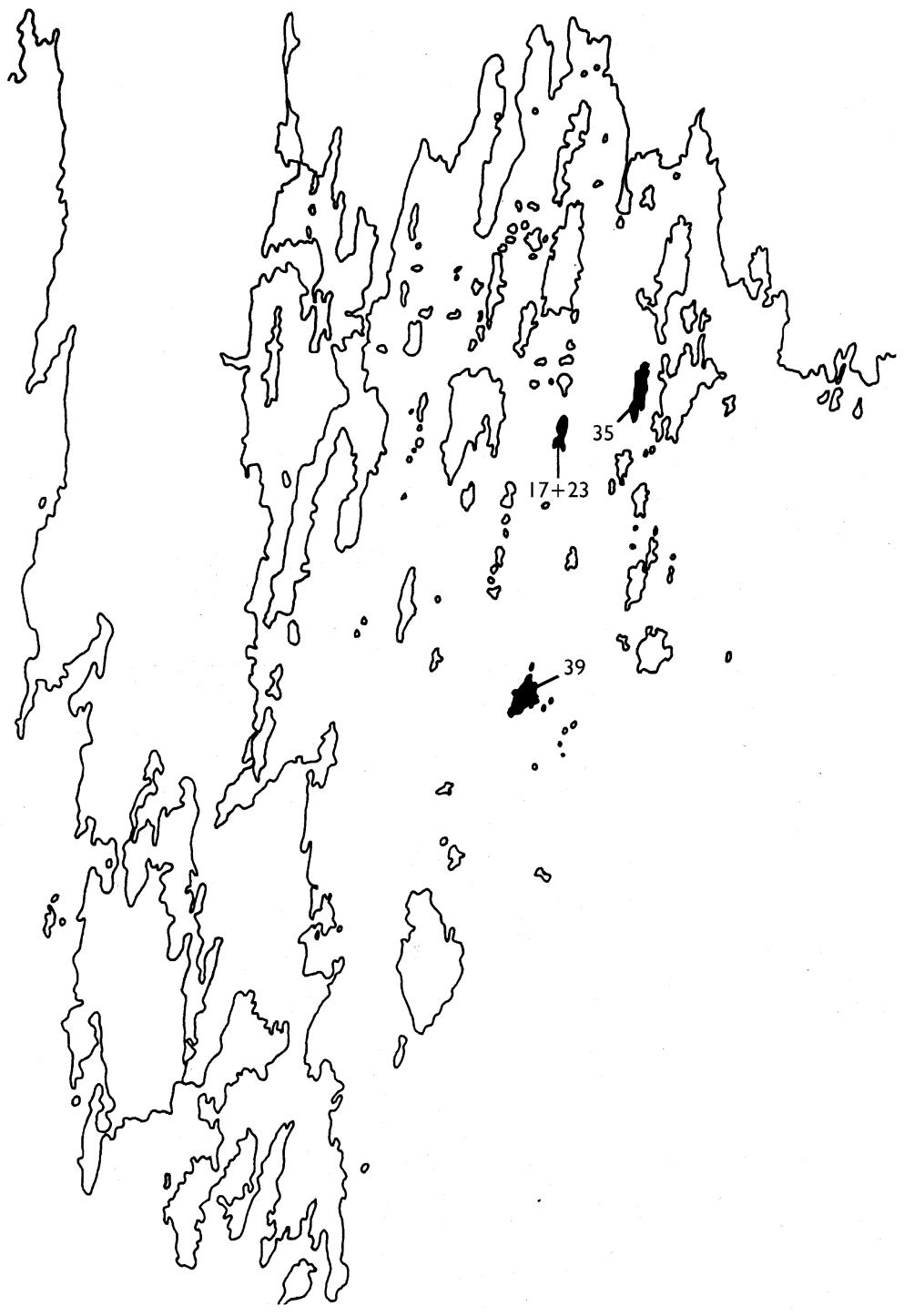


Table 1 Data for populations of Silene dioica from islands of the Skeppsvik Archipelago

\begin{tabular}{lrrccr}
\hline $\begin{array}{l}\text { Island } \\
\text { number }\end{array}$ & $\begin{array}{c}\text { Pop. } \\
\text { age }\end{array}$ & $\begin{array}{c}\text { Pop. } \\
\text { size }\end{array}$ & $F_{\text {IS }}$ & Patches & $N$ \\
\hline 17 & 75 & 3200 & 0.168 & 8 & 75 \\
23 & 96 & 16000 & 0.096 & 31 & 294 \\
35 & 196 & 8500 & 0.040 & 28 & 279 \\
39 & 276 & 18000 & 0.226 & 33 & 329 \\
\hline
\end{tabular}

Island number refers to Fig. 1. Silene dioica population age and size from Carlsson \& Elmqvist (1992). $F_{\text {IS }}$ are within-island values from Giles \& Goudet (1997a). Patches and $N$ refer to the numbers of patches and individuals screened on each island, respectively.

in these patches. 'Census' sizes of the reproductive and total fractions of the minimum breeding units are described by arithmetic means.

\section{Electrophoresis}

Genetic structure was inferred from allozyme data. Individuals were treated as described in Giles \& Goudet (1997a). Nine polymorphic loci were scored from the six enzyme systems, phosphoglucomutase (Pgm, EC 5.4.2.2), phosphoglucoisomerase (Pgi, EC 5.3.1.9), triose-phosphate isomerase (Tpi, EC 5.3.1.1), diaphorase (Dia, EC 1.6.99.-), 6-phosphogluconate dehydrogenase (Pgd, EC 1.1.1.44) and aconitase (Aco, EC 4.2.1.3).

\section{Analyses}

The program FSTAT v. 1.2 (Goudet, 1995) was used to analyse genotypic and allelic compositions and assess deviations from random mating by means of $F$-statistics based on the estimators of Weir \& Cockerham (1984). Conventional two-level hierarchical
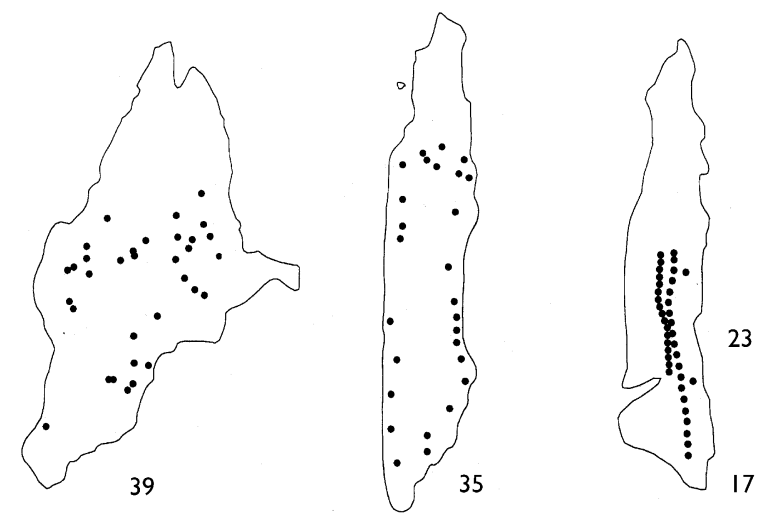

Fig. 2 Patch locations on the study islands. From left to right, islands 39,35 and $17+23$. analyses were carried out for each island separately to show that structuring within islands is a general feature in the archipelago. To keep $F$-statistics terminology consistent with that used in the threelevel hierarchical analysis, we break with the conventional designations of $F_{\mathrm{IS}}$ and $F_{\mathrm{ST}}$. We use the subscripts I for individual, $\mathrm{P}$ for patch, $\mathrm{L}$ for island and $\mathrm{T}$ for total. Thus for each island, $F_{\mathrm{IP}}^{x}$ is the correlation of genes within individuals relative to patches, $F_{\mathrm{PL}}^{x}$ the correlation of genes within patches relative to the island, and $F_{\mathrm{IL}}^{x}$ the correlation of genes within individuals relative to the island ( $x$ is island number). These statistics are related as $\left(1-F_{\mathrm{IL}}\right)=\left(1-F_{\mathrm{IP}}\right)\left(1-F_{\mathrm{PL}}\right)$. The significance of the deviation of each $F$-value from zero was tested using the permutation procedure included in FSTAT. These tests are one-tailed because the alternative hypothesis where genetic drift is suspected is that $F$ will be greater than zero. This test is described in detail in Goudet (1995) and Giles \& Goudet (1997a).

The relative levels of differentiation within and among islands were estimated from three-level heirarchical analyses of gene frequencies (Weir, 1990). The following variance components were computed: within individuals (error term, $\sigma_{\mathrm{w}}^{2}$ ), among individuals within patches $\left(\sigma_{\mathrm{c}}^{2}\right)$, among patches within islands $\left(\sigma_{\mathrm{b}}^{2}\right)$ and among islands $\left(\sigma_{\mathrm{a}}^{2}\right)$. The estimators of genetic differentiation were obtained from these components as: $F_{\mathrm{IP}}=\sigma_{\mathrm{c}}^{2} /\left(\sigma_{\mathrm{w}}^{2}+\sigma_{\mathrm{c}}^{2}\right) ; F_{\mathrm{PL}}=\sigma_{\mathrm{b}}^{2} /$ $\left(\sigma_{\mathrm{b}}^{2}+\sigma_{\mathrm{c}}^{2}+\sigma_{\mathrm{w}}^{2}\right) ; \quad F_{\mathrm{LT}}=\sigma_{\mathrm{a}}^{2} /\left(\sigma_{\mathrm{a}}^{2}+\sigma_{\mathrm{b}}^{2}+\sigma_{\mathrm{c}}^{2}+\sigma_{\mathrm{w}}^{2}\right) ; \quad F_{\mathrm{IL}}=$ $\left(\sigma_{\mathrm{b}}^{2}+\sigma_{\mathrm{c}}^{2}\right) /\left(\sigma_{\mathrm{b}}^{2}+\sigma_{\mathrm{c}}^{2}+\sigma_{\mathrm{w}}^{2}\right) ; \quad F_{\mathrm{PT}}=\left(\sigma_{\mathrm{a}}^{2}+\sigma_{\mathrm{b}}^{2}\right) /\left(\sigma_{\mathrm{a}}^{2}+\sigma_{\mathrm{b}}^{2}+\right.$ $\left.\sigma_{\mathrm{c}}^{2}+\sigma_{\mathrm{w}}^{2}\right) ; F_{\mathrm{IT}}=\left(\sigma_{\mathrm{a}}^{2}+\sigma_{\mathrm{b}}^{2}+\sigma_{\mathrm{c}}^{2}\right) /\left(\sigma_{\mathrm{a}}^{2}+\sigma_{\mathrm{b}}^{2}+\sigma_{\mathrm{c}}^{2}+\sigma_{\mathrm{w}}^{2}\right) . F_{\mathrm{IP}}$, $F_{\mathrm{PL}}$ and $F_{\mathrm{IL}}$ are defined as above; $F_{\mathrm{PT}}$ is the correlation of genes within patches relative to the total, $F_{\mathrm{LT}}$ the correlation of genes within islands relative to the total and $F_{\text {Iт }}$ the correlation of genes within individuals relative to the total. The variance components were estimated using the procedure 'nested' of the Statistical package sas. To obtain per-locus and overall estimators, the ratios of sums rather than the sums of ratios were used as suggested by Weir \& Cockerham (1984).

Before calculating $F$-statistics, we determined whether the variation at all loci appeared to be neutral so that genetic drift could be inferred as the primary force affecting them. This can be assumed if all loci have similar values of $F_{\mathrm{IP}}$ (Slatkin, 1985). A crude test for this is to see whether the confidence intervals of $F_{\text {IP }}$ calculated over populations, overlap or lie between the confidence intervals of $F_{\text {IP }}$ calculated over loci (Goudet et al., 1995). If these overlap, the loci can be assumed to behave in a neutral manner; loci not meeting this criterion should be omitted from further analysis. FSTAT 
calculates these confidence intervals using jackknife procedures (Weir, 1990; Goudet, 1995).

\section{Results}

The over-population confidence intervals (CI) of $F_{\text {IP }}$ for each locus overlapped or lay between the overloci CIs (data not shown), and therefore all nine polymorphic loci were included in the estimation of $F$-statistics.

The gene diversities per locus and over all loci for each of the islands are given in Table 2. Pgm-2, Dia-1 and Pgd-1 have the lowest gene diversities and are therefore the least informative loci; Pgd-2, Pgi-2 and Aco-1 are the most informative. The average diversity was lowest on island 39 , the most isolated island in this study.

$F_{\text {IP }}$ values over all loci for each of the islands are not significantly greater than zero and are negative as expected for a dioecious organism (Table 3).
Differentiation among patches within each of the islands $\left(F_{\mathrm{PL}}^{x}\right)$ is high and significantly greater than zero (Table 3). Populations are thus subdivided on all islands.

Because the $F_{\mathrm{IP}}$ do not indicate structuring within patches, we infer that $0.2 \mathrm{~m}^{2}$ is close to or lies within the minimum size of a random mating unit. Assuming that the transition between two breeding units lies between the closest patches with significant $F_{\mathrm{PL}}^{x}$ values $(2.8 \mathrm{~m}$, data not shown) suggests that breeding units may be as large as $6 \mathrm{~m}^{2}$ (radius $1.4 \mathrm{~m}$ ). A rough idea of the numerical sizes of these units can be obtained from the harmonic mean numbers of reproductive (flowering + nonflowering) and from the arithmetic mean numbers of reproductive and all individuals in the minimum random mating units (Table 4a). These data show that although the total densities of individuals in the minimum mating units vary among islands, the total numbers of individuals are about three times the 'census' numbers of repro-

Table 2 Gene diversities per locus and over all loci for Silene dioica

\begin{tabular}{lcccccccccc}
\hline Island & Pgm-1 & Pgm-2 & Pgi-2 & Tpi-1 & Dia-1 & Pgd-1 & Pgd-2 & Aco-1 & Aco-2 & All loci \\
\hline 17 & 0.32 & 0.10 & 0.45 & 0.10 & 0.27 & 0.15 & 0.63 & 0.51 & 0.09 & 2.61 \\
23 & 0.21 & 0.02 & 0.51 & 0.21 & 0.03 & 0.09 & 0.59 & 0.46 & 0.11 & 2.22 \\
35 & 0.10 & 0.06 & 0.55 & 0.27 & 0.04 & 0.00 & 0.65 & 0.35 & 0.13 & 2.13 \\
39 & 0.28 & 0.01 & 0.35 & 0.07 & 0.00 & 0.07 & 0.52 & 0.33 & 0.28 & 1.90 \\
\hline
\end{tabular}

Table $3 F$-statistics for each island population of Silene dioica (see Materials and methods for subscript definitions)

\begin{tabular}{llccccccccccc}
\hline Island & & Pgm-1 & Pgm-2 & Pgi-2 & Tpi-1 & Dia-1 & Pgd-1 & Pgd-2 & Aco-1 & Aco-2 & All loci & $P$ \\
\hline 17 & No. alleles & 3 & 2 & 4 & 2 & 2 & 2 & 3 & 4 & 3 & & \\
& $F_{\mathrm{PL}}^{17}$ & 0.103 & 0.065 & 0.168 & 0.048 & 0.041 & 0.053 & 0.249 & 0.173 & 0.075 & 0.150 & 0.0002 \\
& $F_{\mathrm{IP}}^{17}$ & -0.185 & -0.115 & -0.156 & 0.182 & -0.221 & -0.113 & -0.013 & 0.049 & -0.111 & -0.079 & 0.96 \\
& $F_{\mathrm{IL}}^{17}$ & -0.063 & -0.042 & 0.038 & 0.221 & -0.171 & -0.074 & 0.238 & 0.213 & -0.028 & 0.083 & 0.002 \\
23 & No. alleles & 3 & 2 & 4 & 2 & 2 & 2 & 3 & 4 & 2 & & \\
& $F_{\mathrm{PL}}^{23}$ & 0.082 & -0.012 & 0.067 & 0.055 & 0.050 & 0.006 & 0.043 & 0.120 & 0.035 & 0.069 & 0.0002 \\
& $F_{\mathrm{IP}}^{23}$ & -0.027 & 0.503 & -0.069 & 0.037 & -0.062 & 0.081 & -0.136 & -0.187 & -0.096 & -0.087 & 0.99 \\
& $F_{\mathrm{IL}}^{23}$ & 0.019 & 0.153 & 0.010 & 0.111 & -0.038 & 0.065 & 0.024 & 0.050 & -0.053 & 0.031 & 0.08 \\
35 & No. alleles & 3 & 2 & 3 & 2 & 2 & 2 & 3 & 4 & 3 & & \\
& $F_{\mathrm{PL}}^{35}$ & 0.004 & 0.013 & 0.030 & 0.031 & 0.002 & -0.002 & 0.031 & 0.169 & 0.001 & 0.049 & 0.0002 \\
& $F_{\mathrm{IP}}^{35}$ & 0.006 & -0.041 & -0.052 & 0.003 & -0.019 & 0.002 & -0.018 & -0.106 & -0.065 & -0.039 & 0.92 \\
& $F_{\mathrm{IL}}^{35}$ & 0.011 & -0.027 & -0.021 & 0.035 & -0.017 & 0.000 & 0.013 & 0.080 & -0.064 & 0.012 & 0.32 \\
39 & No. alleles & 3 & 3 & 3 & 3 & 2 & 3 & 3 & 4 & 3 & & \\
& $F_{\mathrm{PL}}^{39}$ & 0.076 & -0.005 & 0.055 & 0.019 & 0.042 & 0.053 & 0.136 & 0.069 & 0.107 & 0.088 & 0.0002 \\
& $F_{\mathrm{IP}}^{39}$ & 0.049 & 0.001 & -0.048 & -0.051 & -0.046 & -0.089 & -0.137 & 0.106 & -0.014 & -0.027 & 0.87 \\
& $F_{\mathrm{IL}}^{39}$ & 0.121 & -0.004 & 0.010 & -0.031 & -0.002 & -0.032 & 0.018 & 0.168 & 0.094 & 0.064 & 0.002 \\
\hline
\end{tabular}

Number (No.) of alleles observed for each island are given for each locus. $P$ is for the null hypothesis that $F=0$ against the alternative hypothesis that $F>0$. 
Table 4 (a) Numbers of Silene dioica in minimum random mating units estimated from patch data. The numbers of reproductive individuals are described by harmonic ('effective') and arithmetic ('census') means. The arithmetic means of all individuals are also given. $N$ is the number of patches. The standard deviations of arithmetic means are in parentheses. 'E'/All is the ratio of the 'effective' number to the mean total number of individuals per patch. (b) Census sizes of island populations (from Carlsson \& Elmqvist, 1992) and 'effective' numbers of reproductive individuals estimated as patch 'E'/All $\times$ Island 'Census'

\begin{tabular}{|c|c|c|c|c|c|}
\hline \multirow{2}{*}{$\begin{array}{l}\text { (a) Patch level } \\
\text { Island }\end{array}$} & \multirow[b]{2}{*}{$N$} & \multicolumn{2}{|c|}{ Reproductive } & \multirow[b]{2}{*}{ All } & \multirow[b]{2}{*}{ 'E'/All } \\
\hline & & 'Effective' & 'Census' & & \\
\hline 23 & 14 & 2.406 & $4.79(3.12)$ & 12.29 (9.14) & 0.196 \\
\hline 35 & 17 & 2.514 & $3.47(2.30)$ & $9.06(6.61)$ & 0.277 \\
\hline 39 & 18 & 3.724 & $5.72(3.21)$ & 21.17 (15.81) & 0.176 \\
\hline
\end{tabular}

(b) Island level

\begin{tabular}{lcc} 
Island & 'Effective' & 'Census' \\
\hline 23 & 3100 & 16000 \\
35 & 2400 & 8500 \\
39 & 3100 & 18000 \\
\hline
\end{tabular}

ductive individuals. The harmonic mean, our best estimate of the 'effective' number of reproductive individuals, is slightly more than half the reproductive census numbers and averages about three per unit. Thus these data, which have been collected in the same patches from which our estimates of differentiation were obtained, suggest that breeding groups are rather small.
The hierarchical analyses of gene frequencies appear in Table 5. The variance components for the different levels of structure, presented in terms of percentage total variance for within individuals $\left(\sigma_{\mathrm{w}}^{2}\right)$, among patches within islands $\left(\sigma_{\mathrm{a}}^{2}\right)$ and among islands $\left(\sigma_{\mathrm{b}}^{2}\right)$, show that patches within islands are more differentiated than different islands, because there is about twice as much variance within as

Table 5 Variance components and hierarchical $F$-statistics for Silene dioica

\begin{tabular}{|c|c|c|c|c|c|c|c|c|c|c|c|}
\hline \multirow[b]{2}{*}{ Locus } & \multicolumn{5}{|c|}{ Variance components } & \multicolumn{6}{|c|}{ Hierarchical $F$-statistics } \\
\hline & $\sigma_{\mathrm{w}}^{2}$ & $\sigma_{\mathrm{c}}^{2}$ & $\sigma_{\mathrm{b}}^{2}$ & $\sigma_{\mathrm{a}}^{2}$ & $\sigma_{\mathrm{t}}^{2}$ & $F_{\text {IP }}$ & $F_{\mathrm{PL}}$ & $F_{\mathrm{LT}}$ & $F_{\mathrm{PT}}$ & $F_{\mathrm{IL}}$ & $F_{\text {IT }}$ \\
\hline Pgm-1 & 0.199 & 0.001 & 0.015 & 0.006 & 0.220 & -0.007 & 0.071 & 0.026 & 0.095 & 0.074 & 0.088 \\
\hline Pgm-2 & 0.032 & 0.001 & 0.001 & 0.001 & 0.034 & 0.025 & 0.019 & 0.015 & 0.035 & 0.059 & 0.058 \\
\hline Pgi & 0.460 & -0.028 & 0.027 & 0.013 & 0.501 & -0.064 & 0.059 & 0.026 & 0.081 & -0.002 & 0.026 \\
\hline$T p i$ & 0.160 & 0.003 & 0.007 & 0.007 & 0.177 & 0.016 & 0.040 & 0.041 & 0.079 & 0.059 & 0.094 \\
\hline Dia & 0.041 & -0.005 & 0.001 & 0.004 & 0.046 & -0.132 & 0.038 & 0.081 & 0.111 & -0.108 & 0.008 \\
\hline$P g d-1$ & 0.060 & -0.002 & 0.003 & 0.001 & 0.065 & -0.032 & 0.056 & 0.019 & 0.072 & 0.016 & 0.042 \\
\hline$P g d-2$ & 0.578 & -0.049 & 0.057 & 0.061 & 0.696 & -0.092 & 0.097 & 0.088 & 0.169 & 0.014 & 0.099 \\
\hline Aco-1 & 0.340 & -0.007 & 0.045 & 0.015 & 0.401 & -0.020 & 0.118 & 0.038 & 0.149 & 0.101 & 0.133 \\
\hline Aco-2 & 0.175 & -0.006 & 0.013 & 0.004 & 0.192 & -0.037 & 0.073 & 0.021 & 0.090 & 0.038 & 0.057 \\
\hline Overall & 2.045 & -0.094 & 0.169 & 0.112 & 2.332 & -0.048 & 0.080 & 0.048 & 0.121 & 0.035 & 0.080 \\
\hline$\%$ & 87.690 & - & 7.250 & 4.800 & & & & & & & \\
\hline
\end{tabular}

Subscripts are defined in Materials and methods. 
among islands. This is also seen in the hierarchical $F$-statistics where, for both per-locus and overall estimates, $F_{\mathrm{PL}}$ is larger than $F_{\mathrm{LT}}$. The negative component of variance among individuals within patches $\left(\sigma_{\mathrm{c}}^{2}\right)$, which gives a negative $F_{\mathrm{IP}}$, indicates that individuals within patches are more related to each other than to individuals drawn at random from the same island.

\section{Discussion}

The results of this study show that island populations of $S$. dioica in Skeppsvik Archipelago are subdivided into many breeding units. The significantly positive heterozygote deficits within islands reported by Giles \& Goudet (1997a; see also $F_{\text {IS }}$, Table 1) were thus caused by subdivision.

What is striking about these results is the strength of the genetic differentiation among patches and the size of the breeding units. The mean degree of differentiation among patches on these islands $\left(F_{\mathrm{PL}}=0.080\right.$; Table 5) is higher than usually reported for subpopulations of obligately (or predominantly) outbreeding, perennial, animal- or wind-pollinated plants, (Hamrick \& Godt, 1990), including $S$. alba, a species closely related to $S$. dioica and studied on the same spatial scale (McCauley, 1997). Our data indicate that the areas occupied by the breeding units lie between $0.2 \mathrm{~m}^{2}$ and $6 \mathrm{~m}^{2}$. Although further precision is not possible because all plants were sampled from $0.2 \mathrm{~m}^{2}$ patches and the shortest distances between patch centres were $\approx 3 \mathrm{~m}$, differentiation clearly occurs on a fine spatial scale.

If both seed and pollen flow are restricted, local populations may form within continuous arrays and diverge by genetic drift; this is seen as a positive $F_{\mathrm{PL}}$. If the organism is also dioecious and mating is random within local populations, $F_{\text {IP }}$ should be negative (Cockerham, 1973). Our data are not inconsistent with this scenario. However, seed flow is more restricted than pollen flow in our system. This suggests a different hypothesis with which our data are also consistent. Silene dioica seeds disperse by gravity. Circles of even-aged seedlings $\approx 0.5 \mathrm{~m}$ in diameter are observed around isolated females growing on, e.g. newly colonized islands, the shores of islands or in experimental gardens (B. E. Giles, pers. obs.). These patterns imply that female plants could act as nuclei around which patches of plants, consisting of at least half-sib offspring, may develop (Yarranton \& Morrison, 1974). Such family groups could establish at patch founding and persist over generations as female offspring continued to disperse most of their seeds within the same locale.
The coefficient of average relatedness, $r_{\mathrm{L}}=2 F_{\mathrm{PL}} /$ $\left(1+F_{\text {IL }}\right)=0.155$ (Pamilo, 1989; data from Table 5) indicates that individuals within patches are more related to each other than to individuals randomly chosen from other patches within an island. This family structuring has also been confirmed in a further study where plants were sampled contiguously within a $200 \mathrm{~m}^{2}$ area (P. K. Ingvarsson \& B. E. Giles, in prep.). Chesser (1991) showed that substantial differentiation (positive $F_{\mathrm{PL}}$ ) occurs among subdivisions that consist of families even when gene flow by males occurs at random. Chesser's model also predicts that $F_{\mathrm{IP}}$ will be negative because offspring of females fertilized by males outside the patch have a high probability of being heterozygotes. In the archipelago, pollinators move between flowers (10-40) on the same or near-neighbour plants. Flight distances of 1-3 m between nearest-neighbour foraging bouts are common and longer flights occur (B. E. Giles and P. K. Ingvarsson, unpub. obs.). Although gene flow via pollen is not random over the island ( $F_{\mathrm{IL}}$ is positive), it is sufficiently larger than seed dispersal to create a negative $F_{\text {IP }}$ (Chesser, 1991; de Jong et al., 1994). Because $F_{\mathrm{IL}}$ is positive, the family structure alone cannot explain the positive $F_{\mathrm{PL}}$ without also invoking drift.

Gene exchange occurs among islands and among patches within islands in the archipelago. In an island model at drift-migration equilibrium, the average number of migrants exchanged per generation $(\mathrm{Nm})$ is inversely proportional to the levels of genetic differentiation among populations measured as $F_{\mathrm{ST}}$, i.e. $F_{\mathrm{ST}}=1 /(4 N m+1)$, where $N m$ is the product of the effective population size $\left(N_{\mathrm{e}}\right)$ and the migration rate $(m)$ (Wright, 1951). The hierarchical analysis (Table 5) showed that the average degree of differentiation among patches within islands $\left(F_{\mathrm{PL}}=0.08\right)$ was nearly twice that found among islands $\left(F_{\mathrm{LT}}=0.048\right)$. Intuitively, this seems to imply that islands separated by larger distances exchange more migrants than closely situated patches. Support for the expected pattern (Wright, 1978; Slatkin, 1993), that genetic differentiation is higher at larger spatial scales, has been found in some studies (e.g. McCauley \& Eanes, 1987; Heywood, 1991; Rank, 1992; Williams \& Guries, 1994; Husband \& Barrett, 1995), although higher levels of differentiation at local rather than global scales have also been reported (Unruh, 1990; Johannesen \& Loeschcke, 1996; Lönn et al., 1996; Ingvarsson \& Olsson, 1997).

A number of explanations can be advanced to resolve this apparent paradox. First, consider the theoretically expected levels of differentiation among patches and among islands in light of 
Wright's (1951) expression above. The appropriate $\mathrm{Nm}$ term for $F_{\mathrm{PL}}$ is the product of the effective population size of the patch and the rate of migration among patches, whereas that for $F_{\mathrm{LT}}$ is the product of the effective size of the island and the rate of migration among islands (Slatkin \& Voelm, 1991). Although our figures are rough, island population sizes ('effective', Table 4b) are 1000-10000 times larger than patch population sizes ('effective', Table 4a). Thus even if the migration rate among islands were a few orders of magnitude lower than the rate of migration among patches, the larger island population sizes would increase $\mathrm{Nm}$ leading to more migrants exchanged among islands than among patches.

$F_{\mathrm{LT}}$, however, describes the deficiencies of heterozygotes observed on islands relative to those expected from the allele frequencies over all islands, whereas $F_{\mathrm{PL}}$ describes the deficiencies of heterozygotes in patches relative to those expected from the allele frequencies on the islands where the patches are located. Closer examination of colonization and subsequent migration processes for islands and for patches reveal another reason why $F_{\mathrm{LT}}$ may be lower than $F_{\mathrm{PL}}$. Patches and islands are colonized by seeds. Giles \& Goudet (1997a) showed that island colonization followed a migrant pool model, with seeds originating from a random sample of islands. Continued seed and pollen migration are known to occur among islands, and both the founding and migration dynamics suggest that with time, islands obtain the same alleles. Giles \& Goudet (1997a) also found that 30 islands, at the same demographic stage as (and including) the four study islands, contained more alleles (nearly all alleles observed in the archipelago) and were less differentiated than islands at earlier and later successional stages. In contrast, P. K. Ingvarsson \& B. E. Giles (in prep.) show that a population expands over an island through the successive establishment of new patches, each of which is colonized by the related offspring of a single female. In the sense that patches are not founded by individuals drawn as random samples of genotypes available on the entire island, patch colonization more closely resembles a propagule pool model. Given the effects of restricted migration within an island, single patches will not contain the numbers of alleles and types of heterozygotes expected on the basis of the allele frequencies for the entire island. The net effect of these processes will be a relatively high $F_{\mathrm{PL}}$. In contrast, if the actual spatial distribution of genotypes over islands is ignored, the heterozygote deficiencies between islands relative to the allele frequencies over all islands $\left(F_{\mathrm{LT}}\right)$ will not be as high because of the alleles and genotypes shared among islands. The relative strengths of $F_{\mathrm{PL}}$ and $F_{\mathrm{LT}}$ in this study are thus a function of the different processes by which genes are mixed at the two hierarchical levels.

In summary, this study of the distribution of neutral variation has established that $S$. dioica in the Skeppsvik Archipelago is structured at two levels. In theory, the distributions of other genes, including those that code for selectively important characters, at least prior to their selection, should show patterns similar to those indicated by our neutral loci because they are constrained by the same pollen and seed flow patterns. Any future work on evolutionary dynamics in this species which addresses questions of selective changes in gene frequency must be aware of the consequences of the distribution of variation at both levels of the hierarchy.

\section{Acknowledgements}

We thank Astrid Höglund for her excellent work in the laboratory, and Pekka Bader and Katarina Olsson for assistance in the field. The constructive criticisms of John Barrett, Pelle Ingvarsson and an anomymous referee have been invaluable in writing this paper. Grants to B.E.G. from Skogs och Jordbruks Forskningsrådet (SJFR) and Naturvetenskapliga Forskningsrådet (NFR) are gratefully acknowledged. J.G. was supported by the Swiss National Science Foundation (Grant no. 31-43443.95).

\section{References}

BAKER, H. G. 1947. Biological flora of the British Isles. Melandrium (Roehling em.) Fries. J. Ecol., 35, 271-292.

BARTON, N. AND WHITLOCK, M. C. 1997. The evolution of metapopulations. In: Hanski, I. \& Gilpin, M. E. (eds) Metapopulation Dynamics: Ecology, Genetics and Evolution, pp. 183-210. Academic Press, London.

CARLSSON, U. AND ELMQVIST, T. 1992. Epidemiology of anther-smut disease (Microbotryum violaceum) and numeric regulation of populations of Silene dioica. Oecologia, 90, 509-517.

CHESSER, R. K. 1991. Influence of gene flow and breeding tactics on gene diversity within populations. Genetics, 129, 573-583.

COCKerham, C. C. 1973. Analysis of gene frequencies. Genetics, 74, 679-700.

ELMQVIST, T. AND GARDFJELL, H. 1988. Differences in response to defoliation between males and females of Silene dioica. Oecologia, 77, 225-230.

ERICSON, L. AND WALlENTINUS, H.-G. 1979. Sea-shore vegetation around the Gulf of Bothnia. Guide for the International Society for Vegetation Science, July-August, 1977. Wahlenbergia, 5, 1-142.

(C) The Genetical Society of Great Britain, Heredity, 80, 715-723. 
FALCONER, D. S. 1989. Introduction to Quantitative Genetics, 3rd edn. Longman Scientific \& Technical, Harlow, Essex, UK.

GILES, B. E. AND GOUDET, J. 1997a. Genetic differentiation in Silene dioica metapopulations: estimation of spatiotemporal effects in a successional plant species. Am. Nat., 149, 507-526.

GILES, B. E. AND GOUDET, J. 1997b. A case study of genetic structure in a plant metapopulation. In: Hanski, I. and Gilpin, M. E. (eds) Metapopulation Dynamics: Ecology, Genetics and Evolution, pp. 429-454. Academic Press, London.

GOUDET, J. 1995. FSTAT V1.2. A computer program to calculate $F$-statistics. J. Hered., 86, 485-486.

GOUdET, J., DE MEEÜS, T., DAY, A. J. AND GLIDDON, C. J. 1995. The different levels of population structuring of the dogwhelk, Nucella lapillus, along the south Devon coast. In: Beaumont, A. R. (ed.) Genetics and Evolution of Aquatic Organisms, pp. 81-95. Chapman \& Hall, London.

Grime, J. P. 1979. Plant Strategies and Vegetation Processes. John Wiley \& Sons, New York.

HAMRICK, J. L. AND GODT, M. J. 1990. Allozyme diversity in plant species. In: Brown, A. H. D., Clegg, M. T., Kahler, A. L. and Weir, B. S. (eds) Plant Population Genetics, Breeding and Genetic Resources, pp. 43-63. Sinauer Associates, Sunderland, MA.

HANDEL, s. N. 1983. Pollination ecology, plant population structure, and gene flow. In: Real, L. (ed.) Pollination Biology, pp. 163-211. Academic Press, London.

HEYWOOD, J. S. 1991. Spatial analysis of genetic variation in plant populations. Ann. Rev. Ecol. Syst., 22, 335-355.

HUSBAND, B. C. AND BARRETT, s. C. H. 1995. Estimates of gene flow in Eichhornia paniculata (Pontederiaceae): effects of range substructure. Heredity, 75, 549-560.

INVARSSON, P. K. AND OLSSON, K. 1997. Hierarchical genetic structure and effective population sizes in Phalacrus substriatus. Heredity, 79, 153-161.

JOHANNESEN, J. AND LOESCHCKE, v. 1996. A hierarchical analysis of genetic structure and variability in patchily distributed coexisting Chiastocheta species (Diptera: Anthomyiidae). Heredity, 76, 437-448.

JONG, G. DE., DE RUITER, J. R. AND HARING, R. 1994. Genetic structure of a population with social structure and migration. In: Loeschcke, V., Thomiuk, J. and Jain, S. K. (eds) Conservation Genetics, pp. 147-164. Birkhäuser Verlag, Basel.

KAY, Q. O. N., LACK, A. J., BAMBER, F. C. AND DAVIES, C. R. 1984. Differences between sexes in floral morphology, nectar production and insect visits in a dioecious species, Silene dioica. New Phytol., 98, 515-529.

LINHART, Y. B. AND GRANT, M. C. 1996. Evolutionary significance of local genetic differentiation in plants. Ann. Rev. Ecol. Syst., 27, 237-278.

LÖNN, M., PRENTICE, H. C. AND BENGTSSON, K. 1996. Genetic structure, allozyme-habitat associations and reproductive fitness in Gyposophila fastigiata (Caryophyllaceae). Oecologia, 106, 308-316.

McCAULEY, D. E. 1995. Effects of population dynamics on genetics in mosaic landscapes. In: Hansson, L., Fahrig, L. and Merriam, G. (eds) Mosaic Landscapes and Ecological Processes, pp. 178-198. Chapman and Hall, London.

McCAUlEY, D. E. 1997. The relative contributions of seed and pollen movement to the local genetic structure of Silene alba. J. Hered., 88, 257-263.

McCAuley, D. E. AND EANES, W. F. 1987. Hierarchical population structure analysis of the milkweed beetle, Tetraopes tetraophthalmus. Heredity, 58, 193-201.

PAMILO, P. 1989. Estimating relatedness in social groups. Trends Ecol. Evol., 4, 353-355.

RANK, N. E. 1992. A hierarchical analysis of genetic differentiation in a montane leaf beetle Chrysomelia aeneicollis (Coleoptera: Chrysomelidae). Evolution, 46, 1097-1111.

ROBERTSON, A. AND HILl, W. G. 1984. Deviations from Hardy-Weinberg proportions: sampling variances and use in estimation of inbreeding coefficients. Genetics, 107, 703-718.

ROHLF, F. J. AND SCHNEll, G. D. 1971. An investigation of the isolation-by-distance model. Am. Nat., 105, 295-324.

Slatkin, M. 1985. Gene flow in natural populations. Ann. Rev. Ecol. Syst., 16, 393-430.

SLATKIN, M. 1993. Isolation by distance in equilibrium and non-equilibrium populations. Evolution, 47, 264-279.

SLATKIN, M. AND VOELM, L. 1991. $F_{S T}$ in a hierarchical island model. Genetics, 127, 627-629.

TURNER, M. E., STEPHENS, J. C. AND ANDERSON, W. W. 1982. Homozygosity and patch structure in plant populations as a result of nearest-neighbor pollination. Am. Nat., 79, 203-207.

UNRUH, T. R. 1990. Genetic structure among 18 west coast pear psylla populations: implications for the evolution of resistance. Am. Entomol, 36, 37-43.

WeIR, B. S. 1990. Genetic Data Analysis. Sinauer Associates, Sunderland, MA.

WEIR, B. S. AND COCKERHAM, C. C. 1984. Estimating $F$-statistics for the analysis of population structure. Evolution, 43, 1358-1370.

WILliams, C. F. AND GURIES, R. P. 1994. Genetic consequences of seed dispersal in three sympatric forest herbs. I. Hierarchical population-genetic structure. Evolution, 48, 791-805.

WRIGHT, s. 1951. The genetical structure of populations. Ann. Eugen., 15, 323-354.

Wright, s. 1978. Evolution and the Genetics of Populations, Vol. 4, Variability Within and Among Natural Populations. University of Chicago Press, Chicago.

YARRANTON, G. A. AND MORRISON, R. G. 1974. Spatial dynamics of a primary succession: nucleation. J. Ecol., 62, 417-428. 